\title{
Tiga Tema Konsep Kebersyukuran dalam Perspektif Al-Qur'an: Sebuah Literatur Review
}

\author{
Karimulloh \\ Prodi Psikologi, Fakultas Psikologi, Universitas YARSI \\ Email: karimulloh@yarsi.ac.id \\ Novika Grasiaswaty \\ Prodi Psikologi, Fakultas Psikologi, Universitas YARSI \\ Email: novika.grasiaswaty@yarsi.ac.id \\ Riselligia Caninsti \\ Prodi Psikologi, Fakultas Psikologi, Universitas YARSI \\ Email: riselligia.caninsti@yarsi.ac.id
}

Naskah Diterima: 30 Juni 2021, Direvisi: 10 Juli 2021, Disetujui: 14 Juli 2021

\begin{abstract}
This study aims to analyze three themes of the concept of gratitude in the perspective of the Qur'an. There are many blessings received by a human being, but the few people who are considered grateful in the Qur'an are important things to study. Not to mention, not a few studies that discuss gratitude in Indonesia. Mostly talking gratitude from social and individual perspectivem but lack of Islamic literacy, especially from the primary Islamic reference source, namely the Al-Qur'an, is the main objective of this research. The research method used is literature review study by analyzing the verses of gratitude in the Al-Qur'an with a thematic interpretation approach and Islamic science studies. The results of the study show that there are three major themes of the concept of gratitude contained in the Qur'an and supported by the interpretations of the scholars. The three major themes are (1). The command to be grateful in the perspective of the Al Quran, (2) the positive impact of gratitude contained in the Al Quran, and (3) the factors that cause gratitude described in the Al Quran. This result also explains that a grateful person must get the pleasure of Allah SWT, and he will avoid the torment of hellfire and get additional favours, both in this world and in the hereafter. So that someone can be grateful, it is advisable to look at people who are lower in rank, remember the blessings that Allah has given him, and ask Allah SWT to be given the strength to give thanks to Him.
\end{abstract}

Keywords: Gratefulness, Al-Qur'an, Thematic Research

\begin{abstract}
Abstrak
Penelitian ini bertujuan untuk menganalisi tiga tema konsep kebersyukuran Dalam Perspektif Al-Qur'an. Banyak nikmat yang diterima oleh seorang manusia, namun sedikit manusia yang dianggap bersyukur di dalam Al-Qur'an menjadi hal penting untuk dikaji. Belum lagi, tidak sedikit penelitian yang membahas kebersyukuran di Indonesia, namun minimnya literasi keislaman terutama dari sumber referensi utama Islam, yaitu Al-Qur'an menjadi tujuan utama dalam penelitian ini. Metode penelitian yang digunakan adalah studi pustaka dengan menganalisis ayat-ayat
\end{abstract}


kebersyukuran di dalam Al-Qur'an dengan pendekatan tafsir tematik dan studi ilmu keislaman. Hasil penelitian menunjukkan terdapat tiga tema besar konsep kebersyukuran yang tertuang dalam Al Quran dan didukung oleh tafsir para ulama. Ketiga tema besar tersebut adalah (1). Perintah untuk bersyukur dalam perspektif Al Quran, (2) dampak positif dari kebersyukuran yang tertuang dalam Al Quran, dan (3) factor-faktor penyebab kebersyukuran yang dijelaskan di dalam Al Quran. Hasil ini juga menjelaskan bahwa orang yang bersyukur pasti mendapatkan keridhaan Allah SWT, dan dia terhindar dari siksa api neraka, serta mendapatkan tambahan nikmat, baik di dunia maupun di akhirat. Agar seseorang bisa bersyukur, maka dianjurkan untuk melihat orang yang lebih rendah derajatnya, mengingat akan nikmat-nikmat yang telah Allah berikan kepadanya, dan memohon kepada Allah SWT supaya diberi kekuatan untuk bisa bersyukur kepada-Nya.

Kata Kunci: Kebersyukuran, Al-Qur'an,Penelitian Tematik

\section{A. Pendahuluan}

Teori kebersyukuran penting untuk dibahas mengingat dia adalah teori yang mudah, namun sulit untuk diaplikasikan sehingga Allah SWT membuat statemen bahwa "sedikit hamba-Ku yang syukur" dalam surat Saba ayat 13 sebagai berikut:

"Dan sedikit dari 'Ibadi (hamba-hamba-Ku) yang bersyukur."

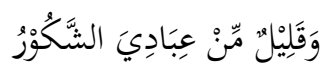

Ayat tersebut dijelaskan oleh Imam Ibnu Katsir bahwa hal tersebut adalah kabar tentang kenyataan atau fakta ${ }^{1}$. Artinya dari 229 juta muslim di Indonesia atau bahkan 1,9 Miliar muslim di dunia pada tahun $2020^{2}$, berapa banyak muslim yang dianggap bersyukur kepada Allah SWT.

Begitu besar peranan kebersyukuran dalam hidup terutama bagi seorang muslim, maka tidak heran jika konstruk ini tidak hanya dijabarkan dalam perspektif Islam tetapi juga dalam literatur psikologi barat yang dikenal dengan gratitude ataupun thankfulness. Perbedaan konsep syukur dan gratitude telah dibahas dalam pemikiran Alddino Gusta Rachmadi ${ }^{3}$. Beberapa perbedaan mendasarnya, yaitu syukur menurut pandangan Islam memuat dan menekankan penerimaan nikmat segala sesuatu didapat dari Khaliq (Pencipta), sementara menurut psikologi barat tidak menyinggung hal tersebut. Selain itu, tujuan dari

\footnotetext{
${ }^{1}$ Abdullah bin Muhammad, Tafsir Ibnu Katsir, Terj. Muhammada Abdul Ghoffar,Bogor: Pustaka Imam Asy-Syafi'i, 2004, Jilid 6, Hlm. 558.

2 Yahya FR, "Data Populasi Penduduk Muslim 2020: Indonesia Terbesar di Dunia" accessed April 8, 2021, https://ibtimes.id/data-populasi-penduduk-muslim-2020-indonesia-terbesar-di-dunia.

3 Alddino Gusta Rachmadi, dkk. "Kebersyukuran: Studi Komparasi Perspektif Psikologi Barat dan Psikologi Islam,” PSIKOLOGIKA: Jurnal Pemikiran dan Penelitian Psikologi, Vol. 24 No. 2 (Juli 2019): 115128, DOI: 10.20885/psikologi.vol24.iss2.art2
} 
rasa syukur menurut Islam juga jelas diperuntukkan kepada Allah SWT, sementara konsep barat tidak mengenal target yang spesifik.

Beberapa penelitian mengenai kebersyukuran dalam Islam telah dilakukan tetapi hanya terfokus pada satu sisi saja. Penelitian yang dilakukan oleh Susanti misalnya, hanya menjelaskan kebersyukuran dari perspektif Islam dari sisi definis saja ${ }^{4}$. Sedangkan penelitian lain yang dilakukan Rachmadi lebih membahas perbandingan kebersyukuran dari Perspektif Psikologi Barat dan Psikologi Islam dari sisi aspek-aspek kebersyukuran itu sendiri dan minim pembahasan dari kitab klasik ${ }^{5}$. Enghariano membahas syukur dari sisi definisi, membandingkan As-Syukru dan Al-hamdu, dan membahas cara bersyukur secara umum, yaitu bersyukur dengan Qolb (hati), bersyukur bil lisan, dan bersyukur bil Jawarih (dengan perbuatan $)^{6}$. Penelitian-penelitian diatas minim akan literasi keislaman terutama dari referensi utama, yaitu Al-Qur'an dan juga studi ilmu keislaman dari berbagai kitab tafsir dan hadits.

Padahal jika dianalisis dari ayat-ayat Al-Qur'an yang menjadi pedoman umat Islam yang telah melewati 21 abad namun tidak pernah berubah ${ }^{7}$, Al-Qur'an itu tidak ada keraguan didalamnya, dia mukjizat dan juga petunjuk bagi orang yang bertakwa. Maka kebersyukuran perspektif Al-Qur'an ini penting untuk dikaji. Bahkan Allah SWT didalam Al-Qur'an sebenarnya telah mengkelompokkan manusia menjadi dua, yaitu kelompok yang bersyukur dan kelompok yang kufur. Hal tersebut Allah tegaskan di dalam surat Al-Insan ayat 3:

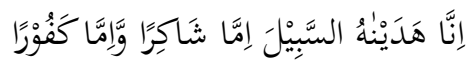

"Sesungguhnya Kami telah memberikan hidayah kepadanya jalan (yang lurus); ada yang syukur dan ada pula yang kufur."

Ayat diatas tidak menggabungkan antara kata شكور dan شفور yang menunjukkan mubalaghah dalam arti bahwa banyak orang syukur dan banyak orang kufur, tetapi Allah SWT menggunakan redaksi شفاكرا yang berarti ada orang yang bersyukur kepada Allah SWT walaupun tidak banyak, namun mayoritas orang kufur kepada Allah SWT ${ }^{8}$.

4 Rizky Susanti, dkk. "Psikoedukasi Kebersyukuran Kepada Tuhan," ALTRUIS: Journal of Community Services, Vol. 1, No. 1, 2020: 25-38. DOI: https://doi.org/10.22219/altruis.v1i1.11545

5 Alddino Gusta Rachmadi, dkk. Op.Cit. 115-128.

${ }^{6}$ Desri Ari Enghariano. "Syukur dalam Perspektif al-Qur'an," Jurnal El-Qanuny: Jurnal Ilmu Kesyariahan dan Pranata Sosial, Vol. 5 No. 2 (Juli-Desember 2019): 270-283. Doi: https://doi.org/10.24952/elqonuniy.v5i2.2154

7 Rif'atul Khoiriah Malik. "HERMENEUTIKA AL-QUR'AN DAN DEBAT TAFSIR MODERN: Implementasinya dengan Masa Kini” At-Turas: Jurnal Studi Keislaman, Vol. 6, No. 1 (Januari-Juni 2019): Hlm. 63. DOI:http://doi.org/10.33650/at-turas.v6i1.583

8 Muhammad Al-Qurthubi. Al-Jami Li Ahkamil Qur'an. (Beirut: Al-Resalah Publishers, 2006). Jilid 21. Hlm. 450. 
Berdasarkan penjelasan diatas, peneliti mencoba untuk mengeluarkan sebagian kecil dari mukjizat Al-Qur'an mengenai siapa saja sebenarnya yang diperintahkan bersyukur dalam Al-Qur'an? Apa dampak-dampak kebersyukuran perspektif Al-Qur'an? Dan apa faktor-faktor yang membuat orang bisa bersyukur sehingga orang tersebut tergolong manusia yang minoritas diantara hamba-hamba-Nya yang mayoritas kurang bersyukur?

\section{B. Metode Penelitian}

Metode penelitian yang digunakan adalah metode studi literatur dengan pendekatan tafsir tematik. Dalam menggunakan metode ini, peneliti menggunakan dua tahap. Pertama, tahap pengumpulan ayat-ayat dari sumber data primer yaitu Al-Qur'An Al-Karim yang sesuai dengan konsep kebersyukuran. Tahapan selanjutnya adalah pengkajian atau analisis data dari tahap pertama dengan menggunakan sumber data sekunder dengan berdasarkan pendekatan tafsir tematik dari kitab-kitab tafsir klasik. Adapun untuk kitab-kitab tafsir klasik yang akan dijadikan refernsi adalah : kitab Ruhul Ma'ani karya Imam Al-Lusy, Al-Jami Li Ahkam Al-Qur'an karya Al-Qurthubi, Tafsir Al-Kasyaf karya Imam Al-Zamakhsyari, Tafsir Miftahul Ghoib karya Imam Ar-Razi, Tafsir At-Thobari karya Imam At-Thobari dan Tafsir Ibnu Katsir karya Ibnu Katsir; Begitu juga dari kitab-kitab hadits, seperti Shohih Al-Bukhori, Shohih Muslim, Sunan Abu Dawud, Al-Jami’ Al-Kabir (Sunan At-Tirmidzi); buku dan artikel-artikel jurnal sehingga ditemukan konsep baru yang lebih relevan dari kebersyukuran perspektif Al-Qur'an untuk menjadi dasar bagi peneliti dari bidang agama Islam dan juga psikologi Islam.

\section{Hasil dan Pembahasan}

Dari kajian literatur yang di dapat, peneliti membahas hasil dari tiga tema besar konsep kebersyukuran dalam Islami yang muncul di Al Quran, yaitu : (1). Perintah bersyukur dalam perspektif Al Quran, (2) dampak positif dari kebersyukuran yang tertuang dalam Al Quran, dan (3) factor-faktor penyebab kebersyukuran yang dijelaskan di dalam Al Quran.

\section{Perintah Bersyukur dalam Al-Qur'an}

Kata syukur diambil dari tiga huruf bahasa Arab, yaitu Syin, Kaf, Ra. Jika ditasrif dalam gramatika Arab menjadi Syakara, Yasykuru, Syukron, wa Syukuron yang memiliki arti mengakui kebaikan dan menceritakannya ${ }^{9}$. Sedangkan menurut istilah, syukur

\footnotetext{
9 Ibnu Mandzur. Lisan Al-Arab. (Bairut: Dar Sadr, 2010). Jilid 4. Hlm. 424.
} 
merupakan melakukan ketaatan dan menjauhi maksiat dengan sungguh-sungguh, baik dalam keadaan sendiri ataupun ramai ${ }^{10}$. Kata syukur berlawanan dengan kufur. Orang yang syukur akan mengakui kebaikan Dzat pemberi nikmat, sedangkan orang kufur tidak mengakuinya. Oleh karena itu, syukur adalah menampakan kenikmatan bagi seorang hamba, baik dengan iman di dalam hatinya, di lisannya dengan memuji Allah SWT, didalam seluruh anggota tubuhnya dengan beribadah dan taat kepada Allah SWT ${ }^{11}$.

Perintah syukur tidak hanya ditujukan kepada umat Muhammad SAW saja, tetapi kepada umat-umat terdahulu, termasuk para Nabinya. Hal tersebut difirmankan oleh Allah SWT:

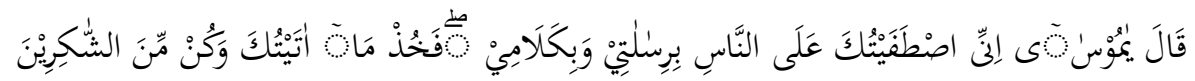

Artinya: (Allah) berfirman, "Wahai Musa! Sesungguhnya Aku memilih (melebihkan) engkau dari manusia yang lain (pada masamu) untuk membawa risalah-Ku dan firman-Ku. Sebab itu berpegang-teguhlah kepada apa yang Aku berikan kepadamu dan hendaklah engkau termasuk orang-orang yang bersyukur."

Ayat ini memerintahkan Nabi Musa AS karena telah diberikan berbagai macam nikmat untuk bersyukur kepada Tuhan, salah satunya adalah nikmat ditunjuk sebagai Nabi dan membawa risalah Allah $\mathrm{SWT}^{12}$. Artinya Para Nabi terdahulu dan juga umatnya diperintahkan untuk bersyukur.

Perintah bersyukur ini bukan ditujukan kepada Khaliq saja, tetapi juga kepada makhluk, diantaranya kedua orangtua. Allah SWT berfirman dalam surat Lukman ayat 14:

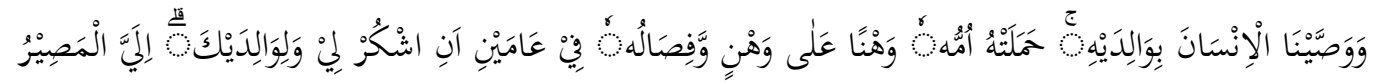

Dan Kami perintahkan kepada manusia (agar berbuat baik) kepada kedua orang tuanya. Ibunya telah mengandungnya dalam keadaan lemah yang bertambahtambah, dan menyapihnya dalam usia dua tahun. Bersyukurlah kepada-Ku dan kepada kedua orang tuamu. Hanya kepada Aku kembalimu.

Ayat tersebut meletakkan secara sejajar antara bersyukur kepada Rabb dan kedua orangtua. Hal tersebut dalam kitab Tanbihul Ghofilin merupakan ayat yang diturunkan saling berpasangan, jika salah satunya terpisah dengan pasangannya maka Allah SWT tidak akan menerimanya. Maksudnya barangsiapa yang bersyukur kepada Allah SWT akan tetapi dia

\footnotetext{
${ }^{10}$ Muhammad Sholih Al-Munjid, Asy-Syukur, Op.Cit. Hlm. 58.

11 Ida Fitri Shobihah. "KEBERSYUKURAN (Upaya Membangun Karakter Bangsa Melalui Figur Ulama)" Jurnal Dakwah, Vol. XV, No. 2 (2014): 387. DOI: https://doi.org/10.14421/jd.2014.15208

12 Ibnu Jarir At-Thobari. Tafsir At-Thabari. (Kairo: Maktabah Ibnu Taimiyah, 2000). Jilid 13. Hlm. 105.
} 
tidak berterima kasih kepada dua orang ibu bapaknya, maka Allah SWT tidak menerima syukurnya ${ }^{13}$. Nabi Muhammad SAW juga bersabda:

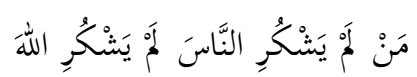

Barangsiapa yang tidak bersyukur kepada manusia maka dia belum bersyukur kepada Allah SWT ${ }^{14}$.

Hadits diatas menunjukkan bahwa syukur kepada manusia, terutama kedua orangtua menjadi syarat akan diterimanya syukur kepada Allah SWT.

Perintah syukur sebenarnya dimulai sejak manusia diciptakan oleh 'Azza Wa Jall. Hal ini termaktub dalam firman-Nya surat An-Nahl ayat 78:

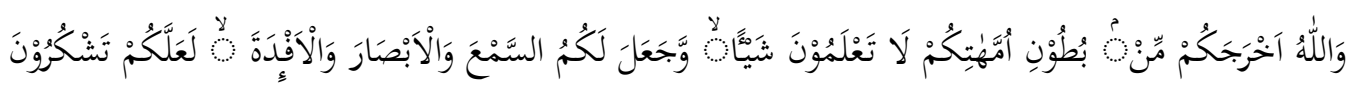

Dan Allah mengeluarkan kamu dari perut ibumu dalam keadaan tidak mengetahui sesuatu pun, dan Dia memberimu pendengaran, penglihatan, dan hati nurani, agar kamu bersyukur.

Ayat diatas menerangkan bahwa manusia dari rahim ibunya dalam keadaan tidak memiliki ilmu atau pengetahuan apapun, baik yang membuatnya bahagia ataupun celaka. Tetapi dengan penglihatan, pendengaran dan perantaraan akal, manusia mengerti sesuatu serta dapat membedakan baik dan buruk. Semua itu merupakan anugerah Pencipta kepada manusia yang tak terhingga supaya manusia bersyukur kepada Allah SWT dan menggunakan semua fasilitas itu sesuai dengan tujuan penciptaannya ${ }^{15}$.

Bahkan dalam Ali Imran ayat 123, artinya: Maka bertakwalah kepada Allah SWT, agar kalian bersyukur. Arti tekstual ayat 123 surat Ali Imran menyatakan bahwa tujuan dari bertakwa sendiri agar manusia bersyukur kepada Allah SWT, yaitu dengan cara beriman kepada keesaan-Nya, segala nikmat-nikmat-Nya dipergunakan untuk patuh melaksanakan ketaatan kepada-Nya ${ }^{16}$. Dari sini, peneliti mengetahui bahwa ibadah dan syukur sangat berhubungan. Artinya orang yang bersyukur sudah pasti beribadah kepada Tuhan Semesta Alam, sedangkan orang yang enggan syukur, dia belum beribadah kepada-Nya. Begitu juga lebih nyata dalam firman Allah SWT surat Al-Baqoroh ayat 172:

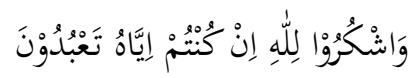

Dan bersyukurlah kepada Allah, jika kamu hanya menyembah kepada-Nya.

\footnotetext{
13 Abu Laits As-Samarkandi. Tanbihul Ghofilin. (Beirut: Dar Ibnu Katsir, 2000). Hlm. 125.

14 Abu Isa At-Turmudzi. Al-Jami' Al-Kabir. (Beirut: Darul gharb Al-Islami, 1996). Jilid 3. Hlm. 506.

15 Mahmud Al-Lusy. Ruhul Ma'ani. (Beirut: Darul Kutub Al-'Alamiyah, 1994). Jilid 7. Hlm. 437-439.

16 Abdullah bin Muhammad, Tafsir Ibnu Katsir, Op.Cit. Jilid 4, Hlm. 130.
} 
Imam Ar-Razi mengartikan ayat ini bahwa apabila kalian ingin menyembah kepada Jalla Jalaluh, maka syukur kepada-Nya adalah hal yang absolut, karena syukur merupakan pangkal ibadah ${ }^{17}$.

Berdasarkan analisis beberapa ayat Al-Qur'an, peneliti menyimpulkan bahwa perintah bersyukur diperintahkan kepada semua manusia, karena bersyukur merupakan inti ibadah. Dan perintah bersyukur tidak dapat ditujukan kepada Allah SWT semata, tetapi harus kepada manusia lainnya, terutama kedua orang tua. Bahkan bersyukur kepada manusia menjadi syarat diterimanya bersyukur kepada Allah SWT.

\section{Dampak Positif Syukur Perspektif Al-Qur'an}

Dampak syukur ini jika diteliti tidak ditujukan untuk Dzat-Nya Allah SWT, namun sebenarnya untuk hamba-Nya sendiri. Sebagaimana perkataan Nabi Sulaiman A.S yang diabadikan dalam An-Naml ayat 40:

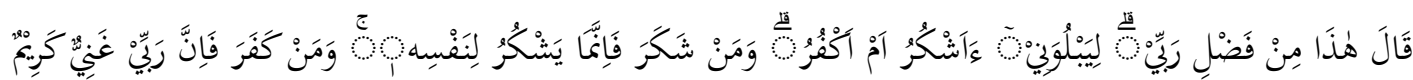

Dia (Sulaiman) berkata, "Ini termasuk karunia Tuhanku untuk mengujiku, apakah aku bersyukur atau mengingkari (nikmat-Nya). Barangsiapa bersyukur, maka sesungguhnya dia bersyukur untuk (kebaikan) dirinya sendiri, dan barangsiapa ingkar, maka sesungguhnya Tuhanku Maha Kaya, Maha Mulia."

Oleh sebab itu, syukur memberikan beberapa dampak positif untuk seorang hamba yang dianalisis dari Al-Qur'an Al-'Adzhim dan Al-Hadits Asy-Syarif sebagai berikut:

a) Al-Qur'an dalam surat An-Nisa ayat 147, Allah SWT berfirman:

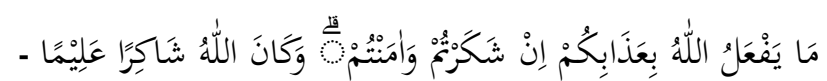

Allah tidak akan menyiksamu, jika kamu bersyukur dan beriman. Dan Allah Maha Mensyukuri, Maha Mengetahui.

Imam Ath-Thabari dalam tafsirnya menjelaskan bahwa orang bersyukur tidak akan diadzab oleh Allah SWT, walaupun awalnya dia munafik, dengan syarat dia bertaubat kepada Allah SWT, kembali kepada yang hak, dan beriman kepada Nabi Muhammad, serta bersyukur atas apa yang telah diberikan kepadanya. Ini adalah janji Subhanahu Wa Ta'ala kepada manusia yang syukur ${ }^{18}$. Bahkan orang munafik pun akan terbebas dari siksa api neraka. Apalagi dia bertakwa dan beriman kepada Allah SWT, tentu dia aman dari murka

17 Muhammad Ar-Razi. Tafsir Al-Fakhrurrazi. (Beirut: Darul Fikr, 1981). Jilid 5. Hlm. 10.

18 Ibnu Jarir At-Thobari. Tafsir At-Thabari. Op.Cit. Jilid 9. Hlm. 342-343. 
Allah SWT. Oleh sebab itu, ditemukan bahwa dampak positif pertama dari orang bersyukur adalah terbebas dari siksa Allah SWT.

b) Al-Qur'an dalam surat Ibrahim ayat 7, Allah SWT berfirman:

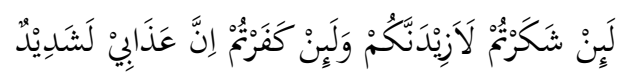

"Sesungguhnya jika kamu bersyukur, niscaya Aku akan menambah (nikmat) kepadamu, tetapi jika kamu mengingkari (nikmat-Ku), maka pasti azab-Ku sangat berat."

Imam Ar-Razi pemilik tafsir Miftahul Ghoib menjelaskan bahwa bertambahnya nikmat bagi orang bersyukur itu terdiri dari berbagai macam, diantaranya: nikmat ruhaniyah dan nikmat jasmaniyah. Nikmat ruhaniyah ini yang akan menyebabkan seorang hamba mencintai Allah SWT. Bahkan kedudukannya lebih tinggi dari pada kedudukan para shiddiqin. Sedangkan bertambahnya nikmat jasmaniyah menyebabkan semakin banyak nikmat yang diterima dan pada akhirnya akan mendapatkan kebahagiaan bagi agama dan dunianya ${ }^{19}$. Ini dampak positif dan juga janji SWT yang akan meningkatkan nikmat-Nya kepada insan-insan pilihan yang selalu bersyukur.

c) Hadits riwayat muslim bahwa Nabi Muhammad SAW bersabda:

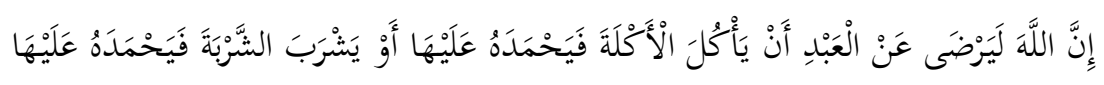

Sesungguhnya Allah SWT benar-benar akan ridha kepada seorang hamba yang memakan suatu makanan kemudian dia memuji Allah atas makanan tersebut, atau seorang hamba yang meminum suatu minuman lalu dia memuji Allah atas minuman tersebut ${ }^{20}$.

Hadits ini dijelaskan oleh Imam Muslim bahwa Allah ridha kepada manusia yang lisannya selalu bersyukur dengan berdzikir kepada Allah SWT. Ini menunjukkan bahwa siapapun yang melakukan demikian berarti hatinya mengakui nikmat Allah SWT dan Allah juga akan ridha kepadanya ${ }^{21}$.

Dampak-dampak positif diatas bagi seorang hamba yang bersyukur pasti terjadi. Bahkan jika dianalisi dari beberapa ayat Al-Qur'an bahwa Allah ternyata tidak menghubungkan antara dampak positif tersebut dengan kehendak-Nya. Artinya balasan bagi orang yang bersyukur itu mutlak akan terjadi. Misalnya firman-Nya dalam ayat 145 surat

\footnotetext{
19 Muhammad Ar-Razi. Tafsir Al-Fakhrurrazi. Op.Cit. Jilid 19. Hlm. 87.

20 Muslim An-Naisaburi. Shohih Muslim. (Riyadh: Dar At-Thaybah, 2006). Jilid 2. Hlm. 1254.

21 Sohrah. "ETIKA MAKAN DAN MINUM DALAM PANDANGAN SYARIAH." Al-Daulah. Vol. 5, No. 1 (Juni, 2016): Hlm. 33. DOI: https://doi.org/10.24252/ad.v5i1.1439
} 
Ali Imran yang artinya: Dan Kami akan memberi balasan kepada orang-orang yang bersyukur. Begitu juga surat surat Ali Imran 144 yang artinya: Allah akan memberi balasan kepada orang yang bersyukur. Didalam kedua ayat tersebut Allah SWT tidak menambahkan: bagi orang yang dikehendaki. Hal ini penting, karena jika seorang mengkaji ayat Al-Qur'an didalam bab rizki dalam ayat 212 surat Al-Baqoroh yang artinya: Dan Allah memberi rizki bagi orang yang dikehendaki. Begitu juga dalam bab taubat, Allah SWT menerangkan dalam ayat 15 surat At-taubah yang artinya: Dan Allah menerima taubat bagi orang yang dikehendaki. Ini semua menunjukkan bahwa potensi positif yang akan diterima bagi orangorang yang bersyukur mutlak adanya, baik berupa terhindar dari adzab, bertambahnya nikmat, dan terpenting Allah SWT ridha kepadanya ${ }^{22}$.

\section{Faktor-faktor Kebersyukuran Perspektif Al-Qur'an dan Al-Hadits}

Faktor-faktor menyebabkan seseorang mampu meningkatkan kebersyukuran jika dianalisis dari perspektif Al-Qur'an Al-Karim dan As-Sunnah An-Nabawiyah ditemukan beberapa faktor sebagai berikut:

\section{a) Mengingat nikmat-nikmat Allah SWT}

Sungguh nikmat dari tubuh saja seperti melihat, menghirup udara, merasakan manis, asin, pahit, dapat bergerak dan sebagainya manusia tidak bisa menghitungnya. Artinya nikmat yang diterima hamba-Nya sangat banyak. Allah SWT menjelaskan:

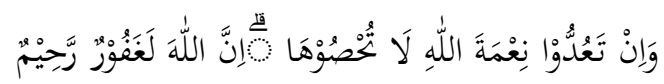

"Dan jika kalian menghitung nikmat Allah, niscaya kalian tidak akan mampu menghitungnya. Sungguh, Allah benar-benar Maha Pengampun, Maha Penyayang."

Hal pertama yang perlu disyukuri oleh seorang hamba ialah nikmat diciptakan (hidup), kemudian nikmat dijadikan sebagai manusia, bukan hewan atau tumbuhan, lalu bersyukur diberi nikmat Iman-Islam, tidak beragama Yahudi, Nashrani atau agama lainnya, dan banyak lagi nikmat Allah SWT.

Bahkan semua makhluk ditundukkan untuk manusia sebagaimana termaktub dalam surat Luqman ayat 20: "Tidakkah kamu memperhatikan bahwa Allah telah menundukkan apa yang ada di langit dan apa yang ada di bumi untuk (kepentingan)mu dan menyempurnakan nikmat-Nya untukmu lahir dan batin." Begitu juga dalam surat Ibrahim ayat 32 - 34: “Allah yang telah menciptakan langit dan bumi dan menurunkan air (hujan) dari langit, kemudian dengan (air hujan) itu Dia mengeluarkan berbagai buah-buahan

\footnotetext{
${ }^{22}$ Muhammad Sholih Al-Munjid, Asy-Syukur, Op.Cit. Hlm. 46.
} 
sebagai rezeki untukmu; dan Dia telah menundukkan kapal bagimu agar berlayar di lautan dengan kehendak-Nya, dan Dia telah menundukkan sungai-sungai bagimu. Dan Dia telah menundukkan matahari dan bulan bagimu yang terus-menerus beredar (dalam orbitnya); dan telah menundukkan malam dan siang bagimu. Dan Dia telah memberikan kepadamu segala apa yang kamu mohonkan kepada-Nya. Dan jika kamu menghitung nikmat Allah, niscaya kamu tidak akan mampu menghitungnya. Sungguh, manusia itu sangat zalim dan sangat mengingkari (nikmat Allah)."

Berdasarkan penjelasan diatas, agar manusia tidak mengingkari nikmatnya, maka perlu untuk mengingat-ingat akan banyaknya nikmat Allah yang diberikan kepada manusia. Suatu ketika Nabi Dawud A.S berkata: "Ya Rabb, bagaimana aku dapat bersyukur kepada$\mathrm{Mu}$, sedangkan syukurku kepada-Mu adalah nikmat dari-Mu kepadaku?" Maka Allah SWT berfirman: "Sekarang engkau telah bersyukur kepada-Ku wahai Dawud". Artinya ketika manusia mengakui bahwa mereka tidak dapat memenuhi syukur yang sepatutnya kepada Pemberi nikmat (Allah), maka saat itu dia dianggap telah bersyukur kepada Allah SWT ${ }^{23}$.

\section{b) Semua nikmat akan dimintai pertanggungjawabkan}

Seorang hamba harus mengetahui bahwa nikmat yang diterima akan dimintai pertanggungjawaban sebagaimana dijelaskan dalam surat At-Takatsur ayat 8:

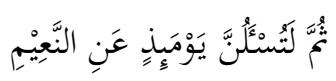

"kemudian kamu benar-benar akan ditanya pada hari itu tentang kenikmatan."

Ibnu katsir menjelaskan bahwa kenikmatan yang dimaksud dalam ayat tersebut adalah kesehatan badan, pendengaran dan penglihatan. Allah SWT akan menanyakan kepada semua hamba untuk apa semua itu mereka pergunakan. Ibnu katsir mengutip surat Al-Israa ayat 36 yang artinya: Sesungguhnya pendengaran, penglihatan dan hati. Semua itu akan dimintai pertanggungjawabannya. Beliau juga mengutip sabda Rasulullah SAW yang diriwayatkan oleh Imam Al-Bukhori:

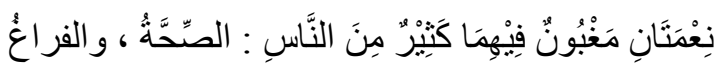

Dua nikmat yang membuat banyak orang tertipu olehnya, yaitu nikmat sehat dan waktu luang ${ }^{24}$.

Hal tersebut berarti bahwa banyak orang terlalu sedikit mensyukuri kedua nikmat tersebut, dimana mereka tidak menunaikan kewajiban yang dituntut keduanya. Oleh sebab

23 Abdullah bin Muhammad, Tafsir Ibnu Katsir, Op.Cit. Jilid 13, Hlm. 546.

${ }^{24}$ Muhammad Al-Bukhori. Shohih Al-Bukhori. (Bairut: Dar Ibnu Katsir, 2002). Hlm. 1598. 
itu, seorang hamba yang mengingat akan pertanggungjawab di hadapan Allah SWT akan menjalankan kewajibannya. Sedangkan orang yang tidak menunaikan hak yang diwajibkan atasnya berarti dia tidak bersyukur dan dia telah tertipu ${ }^{25}$.

\section{c) Melihat orang yang lebih bawah derajatnya}

Nabi Muhammad SAW bersabda dalam riwayat Imam At-Turmidzi:

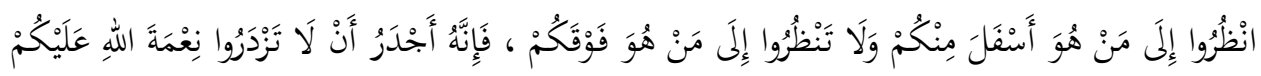

Lihatlah kepada orang yang lebih bawah dari kalian, dan janganlah kalian melihat kepada orang yang berada diatas kalian, maka hal tersebut lebih pantas bagi kalian agar tidak memandang rendah nikmat Allah yang diberikan kepada kalian ${ }^{26}$.

Hadits ini mengabarkan bahwa manusia yang memandang kepada orang yang berada dibawahnya dalam hal dunia maka mereka akan bersyukur atas pemberian yang diterima. Sedangkan orang yang memandang kepada orang yang lebih kaya darinya maka dia akan kecewa dan tidak bersyukur kepada Allah SWT.

Uniknya ternyata dalam kitab Musnaf Ibnu Abi Syaibah dikatakan bahwa Nabi Adam A.S. ketika ditampakan keturunannya melihat bahwa sebagian keturunannya lebih utama dari pada sebagian yang lain. Beliau A.S. berkata, "Tuhanku, seandainya disamakan diantara mereka". Allah SWT berfirman, "Wahai Adam, sesungguhnya aku mencintai rasa syukur, maka orang yang memiliki keutamaan akan melihat keutamaannya dan dia memujiku dan bersyukur kepadaku" ${ }^{27}$. Hadits ini menjelaskan bahwa Tuhan memang membuat manusia dengan derajat yang berbeda-beda seperti Firman-Nya:

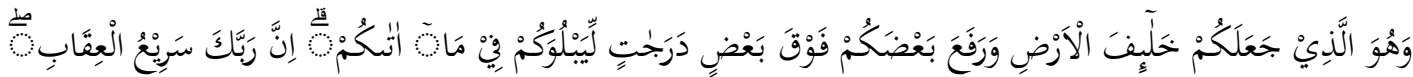

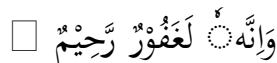

Dan Dialah yang menjadikan kalian sebagai khalifah-khalifah di bumi dan Dia mengangkat (derajat) sebagian kalian di atas yang lain, untuk menguji kalian atas (karunia) yang diberikan-Nya kepada kalian. Sesungguhnya Tuhanmu sangat cepat memberi hukuman dan sungguh Dia Maha Pengampun, Maha Penyayang.

Menurut Az-Zamakhsyari maksud dari kalimat “untuk menguji kalian atas (karunia) yang diberikan-Nya" adalah bagaimana kalian bersyukur atas nikmat-nikmat tersebut. Salah satu caranya dengan melihat orang yang lebih bawah derajatnya ${ }^{28}$.

\footnotetext{
25 Abdullah bin Muhammad, Tafsir Ibnu Katsir, Op.Cit. Jilid 30, Hlm. 534.

26 Abu Isa At-Turmudzi. Al-Jami' Al-Kabir. Op.Cit. Jilid 4. Hlm. 282.

27 Abdullah Ibnu Abi Syaibah. Al-Mushonnaf. (Riyadh: Maktabah Ar-Rusyd, 2004). Jilid 12. Hlm. 366.

28 Abu Al-Qosim Al-Zamakhsyari. Tafsir Al-Kasyaf. (Bairut: Darul Ma'rifah, 2009). Jilid 8. Hlm. 355.
} 


\section{d) Berdoa agar diberi pertolongan untuk bersyukur}

Faktor penting lain supaya seseorang bisa bersyukur adalah dengan berdoa sebagaimana Nabi Muhammad membimbing Muadz bin Jabal agar tidak pernah meninggalkan doa ini setelah selesai sholat:

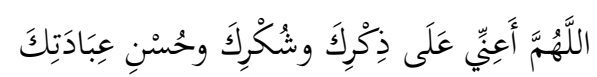

Ya Allah, Bantulah aku untuk mengingat-Mu, bersyukur kepada-Mu, dan

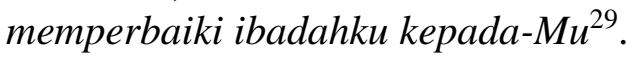

Hadits tersebut menunjukkan bahwa syukur juga perlu bantuan dari Allah SWT, tidak cukup usaha manusia sendiri. Manusia mempunyai kehendak bebas, namun kehendak bebas manusia ditentukan atas izin dari kehendak Allah SWT, maka seharusnya manusia meminta kepada Dzat yang Maha Berkehendak untuk bisa selalu taat dan bersyukur kepadaNya.

\section{Penutup}

Penelitian ini dapat disimpulkan, berdasarkan analisis dari ayat-ayat syukur dengan pendekatan kitab-kitab tafsir dan beberapa hadits, maka dinyatakan bahwa perintah bersyukur bukan hanya difokuskan umat Rasulullah SAW saja, melainkan semua insan, juga umat-umat terdahulu. Kebersyukuran ini bukan ditentukan dari kaya atau miskin seseorang, kuat atau lemahnya, tetapi dia adalah hidayah Allah yang dipasrahkan kepada ciptaan-Nya yang diinginkan. Orang yang bisa bersyukur maka dia akan memperoleh keridhaan serta kasih sayang Allah SWT, sehingga terbebas dari siksa api neraka, dan juga memperoleh tambahan nikmat lainnya. Untuk bisa bersyukur, maka diperlukan melihat orang yang lebih bawah derajatnya, mengingat akan anugrah yang telah Allah turunkan, mengingat hari pertanggungjawaban, lalu berdoa supaya diberi kemudahan untuk bersyukur.

29 Abu Dawud. Sunan Abi Dawud. (Bairut: Dar Al-Risalah Al-'Alamiyah, 2009). Jilid 2. Hlm. 631. 


\section{DAFTAR PUSTAKA}

AL-Bukhari, M. bin I. (n.d.). Shahih al-Bukhari. Dar Thauq al-Najat.

Al-Lusy, M. (1994). Ruhul Ma'ani. Darul Kutub Al-'Alamiyah.

Al-Munjid, M. S. (2009). Asy-Syukur. Zad Group.

Al-Qurthubi, M. (2006). Al-Jami Li Ahkamil Qur'an. Al-Resalah Publishers.

Al-Zamakhsary, A. A.-Q. (2009). Tafsir Al-Kasyaf. Darul Ma'rifah.

Alddino Gusta Rachmadi, D. (2004). Kebersyukuran: Studi Komparasi Perspektif

Psikologi Barat dan Psikologi Islam. PSIKOLOGIKA: Jurnal Pemikiran Dan

Penelitian Psikologi, 24(2).

An-Naisaburi, M. (2006). Shohih Muslim. Dar At-Thaybah.

Ar-Razi, M. (1981). Tafsir Al-Fakhrurrazi. Dar al-Fikr.

As-Samarkandi, A. L. (2000). Tanbihul Ghofilin. Dar Ibnu Katsir.

At-Thobari, I. J. (2000). Tafsir At-Thabari. Maktabah Ibnu Taimiyah.

At-Turmudzi, A. I. (1996). Al-Jami’ Al-Kabir. Darul gharb Al-Islami.

Engharian, D. A. (2019). Syukur dalam Perspektif al-Qur'an. Jurnal El-Qanuny. Jurnal Ilmu Kesyariahan Dan Pranata Sosial, 5(2).

Malik, R. K. (2019). Hermeneutika Al-Qur'an dan Debat Tafsir Modern: Implementasinya dengan Masa Kini. At-Turas: Jurnal Studi Keislaman, 6(1).

Mandzu, I. (2010). Lisan Al-Arab. Dar Sadr.

Muhammad, A. (n.d.). Tafsir Ibnu Katsir. Pustaka Imam Asy-Syafi'I.

Rizky Susanti, D. (2020). Psikoedukasi Kebersyukuran Kepada Tuhan. ALTRUIS: Journal of Community Services, 1(1).

Shohibah, I. F. (2014). KEBERSYUKURAN (Upaya Membangun Karakter Bangsa Melalui Figur Ulama). Jurnal Dakwah, 15(2).

Sohrah. (2020). Etika Makan dan Minum Dalam Pandangan Syariah. Al-Daulah, 1(1).

Syaibah, A. I. A. (2004). Al-Mushonnaf. Maktabah Ar-Rusyd. 